\title{
Testing Purchasing Power Parity Hypothesis for Azerbaijan
}

\author{
Seymur Agazade \\ Recep Tayyip Erdoğan University, Turkey
}

\section{Introduction}

The Purchasing Power Parity (PPP) hypothesis predicts that exchange rates are determined by the purchasing power of national currencies. This hypothesis implies equalization or co-movement of foreign and domestic good prices in longrun when prices expressed in the same currency, although there can be short-run deviations. The PPP hypothesis can be seen as international form of the law of one price. Under some assumptions, the law of one price foresees that identical goods must have the same prices in different markets. Transaction cost such as transportation, restrictions on free trade like quotas and custom tariffs, arbitrage preventing constraints can invalidate the PPP hypothesis. As well as price and exchange rate interventions, the presence of nontradable goods, the volume of initially-invested capital and differences between the goods or their weights included in the price indices of countries may cause to the PPP deviations or may cause not to guarantee the PPP hypothesis.

The absolute form of PPP hypothesis assumes there are no transaction costs or trade restrictions, and price indices measure the same thing. So, according to this view the exchange rate; the foreign currency per unit of domestic currency $(E)$, must be equal to the ratio of the foreign price level $\left(\mathrm{P}_{\mathrm{F}}\right)$ and the domestic price level $\left(\mathrm{P}_{\mathrm{D}}\right)$, i.e.:

$$
\mathrm{E}=\mathrm{P}_{\mathrm{F}} / \mathrm{P}_{\mathrm{D}}
$$

We can also express the PPP hypothesis in terms of the real exchange rate (RER, from now on). Absolute version of the PPP hypothesis predicts that RER must be equal to one.

$$
\mathrm{RER}=\mathrm{EP}_{\mathrm{D}} / \mathrm{P}_{\mathrm{F}}=1
$$

As stated, many factors may result in rejection of the absolute form of PPP. The relative form of PPP hypothesis predicts not to equalization but co-movement foreign and domestic prices. At this point, time series characteristics of deviations have important implications concerning to the validity of relative PPP hypothesis. 
If deviations from long-run equilibrium level of RER are temporary, RER will be stationary. Stationarity of RER is an expression of the validity of the relative PPP hypothesis.

Existing literature presents limited studies that empirically test the validity of the PPP hypothesis for Azerbaijan. Findings of the studies do not provide strong common conclusion, even if considering the approaches and the numeraire currencies. Among the studies, Solakoglu (2006) performed panel unit root approaches for annual data of 22 transition economies and his findings suggest that the PPP hypothesis is applicable for transition economies. Doğanlar (2006) and Bahmani-Oskooee et al. (2009) employed linear time series approaches and their results contradict each other. By using linear cointegration tests and US dollar as numeriare currency, Doğanlar (2006) does not found any support in favor of the PPP hypothesis for Azerbaijan. But, preferring to examine the stationary characteristics of real effective exchange rate, Bahmani-Oskooee et al. (2009) found that the PPP hypothesis holds for Azerbaijan. Bahmani-Oskooee et al. (2008), Telatar and Hasanov (2009), Liew, Chia and Ling (2010) and Liew et al. (2010) performed tests that taking into account the nonlinear adjustment characteristics of the PPP. By using real effective exchange rate series for 88 countries including transition economies, Bahmani-Oskooee et al. (2008) concluded the PPP hypothesis is invalid for Azerbaijan. By contrast, Liew, Chia and Ling (2010) and Liew et al. (2010) applying nonlinear cointegration tests reached to the opposite conclusion that RER of AZN versus USA is adjusted nonlinearly and asymmetrically respectively. In a study of ten Soviet transition economies, Telatar and Hasanov (2009) also found that the PPP hypothesis holds for Azerbaijan, only if both structural breaks and asymmetries are taken into account.

The remainder of this paper is organized as follows. Section II briefly explains the alternative unit root test methodologies. Section III shows our empirical results and Section IV concludes.

\section{Methodology}

The time series characteristics of the RER series present inferences related to the validity of the PPP hypothesis. The long-run validity of the PPP hypothesis can be analyzed by using unit root tests. In this paper six different unit root tests are conducted to investigate the stationary characteristics of the RER of AZN versus four major trading partners of Azerbaijan. These tests are augmented Dickey and Fuller (1979; hereafter, ADF) test, Zivot and Andrews (1992; hereafter, ZA) test, and four nonlinear tests that take into account different possibilities regarding nonlinearities of long-run adjustment. The ADF approach tests the unit root against 
a linear trend stationarity. The ZA test is a linear unit root test and allows for one endogenously determined structural break in the intercept, the linear trend or in both. Because these two tests have common and familiar application in the existing literature, methodical explanation related to them are not given here.

After the break-up of the Soviet Union in the 1990, Azerbaijan left centrally planned economy and realized numerous market oriented structural reforms in the years of transition period. The equilibrium level of the RER may probably effected by the structural changes. So implementing unit root tests that allows for structural changes or nonlinear adjustments may give more accurate results related to the validity of the PPP hypothesis for this country.

The first nonlinear unit root test applied in this paper is Bierens (1997) approach that tests the unit root with drift hypothesis against a very general trend stationarity. Bierens (1997) test is based on the following ADF-type auxiliary regression:

$$
\Delta \mathrm{z}_{\mathrm{t}}=\alpha \mathrm{z}_{\mathrm{t}-1}+\sum_{\mathrm{j}=1}^{\mathrm{p}} \phi_{\mathrm{j}} \Delta \mathrm{z}_{\mathrm{t}-\mathrm{j}}+\theta^{\mathrm{T}} \mathrm{P}_{\mathrm{t} \mathrm{n}}^{(\mathrm{m})}+\varepsilon_{\mathrm{t}}
$$

where $\mathrm{P}_{\mathrm{t} \mathrm{n}}^{(\mathrm{m})}$ represents a vector of Chebyshev polynomials that orthogonal to the time trend. $P_{t_{2} 0}^{(m)}$ equals to one, $P_{t_{s} 1}^{(m)}$ is corresponding to a linear trend, and $P_{t_{s} 2}^{(m)}$ trough $\mathrm{P}_{\mathrm{t}_{\mathrm{m}} \mathrm{m}}^{(\mathrm{m})}$ are cosine functions (Bierens, 1997, 31-32). Null hypothesis is that $\alpha$ and the last $\mathrm{m}$ (order of polynomial) components of $\theta^{\mathrm{T}}$ equal to zero. The unit root hypothesis is tested with the $t$-statistics of $t(m)$, the test statistic $\widehat{\mathrm{A}}(\mathrm{m})=\mathrm{n} \hat{\alpha} /\left(1-\sum_{\mathrm{j}=1}^{\mathrm{p}} \widehat{\phi}_{\mathrm{j}}\right)$, and the $\mathrm{F}$-test $(\widehat{\mathrm{F}}(\mathrm{m}))$ for the joint hypothesis that $\alpha$ and the last $m$ components of $\theta$ equal to zero. Bieres (1997) reports fractiles of the null distribution of $\mathrm{t}(\mathrm{m}), \widehat{\mathrm{A}}(\mathrm{m})$, and $\widehat{\mathrm{F}}(\mathrm{m})$ for $\mathrm{m}$ equal up to 20 and does not offer any definitive method for choosing $\mathrm{m}$. If $\mathrm{m}$ is low, it may cause not to catch the nonlinearity. If $\mathrm{m}$ is high, it may cause the test to low power.

Second nonlinear test is proposed by Leybourne et al. (1998; hereafter, LNV). The LNV test models structural change as a smooth transition between different regimes over time rather than as an instantaneous structural break. The LNV unit root test is based on the following three logistic smooth transition regressions:

$$
\begin{gathered}
y_{\mathrm{t}=} \alpha_{1}+\alpha_{2} \mathrm{~S}_{\mathrm{t}}(\gamma, \tau)+\mathrm{v}_{\mathrm{t}} \\
\mathrm{y}_{\mathrm{t}=} \alpha_{1}+\beta_{1} \mathrm{t}+\alpha_{2} \mathrm{~S}_{\mathrm{t}}(\gamma, \tau)+\mathrm{v}_{\mathrm{t}} \\
\mathrm{y}_{\mathrm{t}=\alpha_{1}}+\beta_{1} \mathrm{t}+\alpha_{2} \mathrm{~S}_{\mathrm{t}}(\gamma, \tau)+\beta_{2} \mathrm{t} \mathrm{S}_{\mathrm{t}}(\gamma, \tau)+\mathrm{v}_{\mathrm{t}}
\end{gathered}
$$


where $\mathrm{S}_{\mathrm{t}}(\gamma, \tau)$ is a logistic smooth transition function which controls transition between regimes. Equation 4, 5 and 6 suppose the nonlinear component as transition in the intercept of nontrending, in the intercept of trending and, in the intercept and slope of trending series respectively. The logistic smooth transition function is based on the sample size of $T$ and expressed as, $\mathrm{S}_{\mathrm{t}}(\gamma, \tau)=[1+\exp \{-\gamma(\mathrm{t}-\tau \mathrm{T})\}]^{-1}$. The parameter $\tau$ determines the timing of the transition midpoint. This logistic function does impose certain restrictions, in that the transition path is monotonic and symmetric around the midpoint and the transitions in intercept and slope to occur once only, simultaneously, and with the same speed (LNV, 1998, 85). Application of the LNV test involves two steps. In the first step, the models A, B or C are estimated by nonlinear least squares and the residuals are computed. In the second step, the ADF test is employed to the residuals.

Third nonlinear test applied to Azerbaijan's RER series is Kapetanios et al. (2003; hereafter, KSS) test. KSS test detects nonstationarity against globally stationary exponential smooth transition autoregressive processes and based on the following exponential model:

$$
\Delta y_{t}=\sum_{j=1}^{p} \rho \Delta y_{t-j}+\gamma y_{t-1}\left\{1-\exp \left(-\theta y_{t-1}^{2}\right)\right\}+\varepsilon_{t}
$$

KSS focuses on the speed of mean reversion parameter, $\theta$, which is zero under the null $(\theta=0)$ and positive under the alternative $(\theta>0)$. Testing the null hypothesis directly is not feasible, since $\gamma$ is not identified under the null. To overcome this problem, KSS compute a first-order Talyor series approximation to the Equation 8 under the null and obtain the following auxiliary regression:

$$
\Delta y_{t}=\sum_{j=1}^{p} \rho \Delta y_{t-j}+\delta y_{t-1}^{3}+e_{t}
$$

Null hypothesis of unit root to be tested is $t$-statistics for $\delta=0$ against the alternative of nonlinear stationarity, $\delta<0$.

The final nonlinear test implemented in this paper is Cuestas and Ordóñez (2014; hereafter, $\mathrm{CO}$ ) unit root test that accounts for nonlinear deterministic trend and asymmetric adjustment. $\mathrm{CO}$ test takes into account two sources of nonlinearities in data, i.e. asymmetric speed of mean reversion and structural changes and considers the following model:

$$
y_{t}=g(t)+\epsilon_{t}
$$

where $g(t)$ is a nonconstant function of time. In order to take into account the possibility of asymmetric adjustment CO propose to apply the KSS unit root test to 
the $\epsilon_{\mathrm{t}}$. In Equation $9 \mathrm{~g}(\mathrm{t})$ is modeled as $\mathrm{g}(\mathrm{t})=\mathrm{g}_{1}+\mathrm{g}_{2} \mathrm{t}+\mathrm{g}_{3} \mathrm{~L}_{\mathrm{t}}(\gamma)+\mathrm{g}_{4} \mathrm{tL}_{\mathrm{t}}(\gamma)$, where $\mathrm{L}_{\mathrm{t}}(\gamma)$ is a logistic smooth transition function defined as $\mathrm{L}_{\mathrm{t}}(\gamma)=1 /\left(1+\mathrm{e}^{-\gamma \mathrm{t}}\right)$.

\section{Data and Empirical Results}

The data used in the present study was taken from the Central Bank of the Azerbaijan Republic and World Bank Global Economic Monitor Data Base. The analysis covers the period from January 1995 to May 2012. Foreign countries are USA, European Union, Russia and Turkey. For full study period exchange rate data of AZN versus Euro and Turkish lira is not available, therefore they were calculated as cross exchange rate of USD. CPI series of all countries are seasonally adjusted and recomputed as 2005:1 $=100$.

In Table 1 summarized the results of traditional linear ADF unit root test specifications. They based on various assumptions regarding the choice of deterministic components. All three specifications of ADF unit root tests are unable to reject nonstationarity at $10 \%$, indicating that the behavior of all various RER series of AZN are unit root processes and the deviations from the long-run equilibrium level are not mean reverting.

The ZA approach that tests unit root with a single endogenously determined break may explore the structural changes. The ZA unit root test results obtained from three models reported in Table 2 and support stationarity of RER when USD and Turkish lira used as numeriary currencies.

Table 1. The ADF test results

\begin{tabular}{|l|c|c|c|}
\hline \multicolumn{1}{|c|}{ RER of AZN } & Intercept & Trend stationary & $\begin{array}{c}\text { Zero-mean } \\
\text { stationary }\end{array}$ \\
\hline USD & $-0.121(1)$ & $-0.854(1)$ & $1.787(1)$ \\
\hline EUR & $-1.124(1)$ & $-1.496(1)$ & $1.325(1)$ \\
\hline RUB & $-2.025(0)$ & $-2.095(0)$ & $-0.290(0)$ \\
\hline TRY & $-2.099(1)$ & $-2.139(1)$ & $-0.015(1)$ \\
\hline
\end{tabular}

Not: The lag lengths given in brackets are selected by minimizing the Schwarz Information Criterion.

Table 2. Zivot and Andrews (1992) unit root test result

\begin{tabular}{|l|l|l|l|}
\hline RER of AZN & Mean & Slope & Mean and slope \\
\hline USD & -3.549 & $\mathbf{- 4 . 6 5 6}$ & -4.025 \\
\hline EUR & -3.445 & -3.723 & -4.191 \\
\hline
\end{tabular}




\begin{tabular}{|l|l|l|l|}
\hline RUB & -2.875 & -2.372 & -3.488 \\
\hline TRY & -3.979 & $-\mathbf{4 . 1 8 8}$ & -4.106 \\
\hline $10 \%$ critical values & -4.58 & -4.11 & -4.82 \\
\hline
\end{tabular}

Not: Critical values are based on Zivot and Andrews (1992). Bold numbers indicate rejection of the null hypothesis of unit root at the $10 \%$.

The results of Bierens (1997), LNV and KKS tests are reported in Tables 3, 4 and 5 respectively. Bierens (1997) takes structural changes into account approximating the nonlinear deterministic time trend by Chebishev time polynomials. Following Bierens (1997) the order of time polynomial is set at $m=10$, but test statistics of lower or higher $\mathrm{m}$ indicate the same results (not reported). In this test, the side of the rejection of the null hypothesis has some inferences over the linearity. $t$ and $\mathrm{A}(\mathrm{m})$ tests are two sided. While left side rejection of null implies either mean stationarity, linear trend stationarity or nonlinear stationarity, but right hand rejection favors the nonlinear trend stationarity. On the other hand, $F(m)$ test is one tailed and do not make distinction over the linearity. According to the Bierens (1997) unit root test findings that presented in Table 3, the null of unit root can be rejected in one case when RER is defined by USD and in consideration of $F(\mathrm{~m})$ statistic. For other definitions of RER it is impossible to reject the null hypothesis of unit root against the alternative of nonlinear or linear trend stationarity.

Table 3. Bierens (1997) unit root test result

\begin{tabular}{|c|c|c|c|c|}
\hline \multicolumn{2}{|l|}{ RER of AZN } & $\mathrm{t}$ & $\mathrm{A}(\mathrm{m})$ & $\mathrm{F}(\mathrm{m})$ \\
\hline \multicolumn{2}{|l|}{ USD } & $-6.267(1)$ & $-68.073(1)$ & $6.384(1)$ \\
\hline \multicolumn{2}{|l|}{ EUR } & $-5.841(1)$ & $-70.546(1)$ & $4.369(1)$ \\
\hline \multicolumn{2}{|l|}{ RUB } & $-4.747(0)$ & $-45.040(0)$ & $2.744(0)$ \\
\hline \multicolumn{2}{|l|}{ TRY } & $-5.752(1)$ & $-69.799(1)$ & $3.988(1)$ \\
\hline \multirow{2}{*}{$\begin{array}{l}\text { Fractiles of the } \\
\text { asymptotic null } \\
\text { distribution }\end{array}$} & $10 \%$ & -6.29 & -73.70 & 2.36 \\
\hline & $90 \%$ & -4.17 & -36.60 & 4.60 \\
\hline
\end{tabular}

Not: Lag lengths given in brackets are selected by minimizing the SCI. Bold numbers indicate rejection of the null hypothesis of unit root at the $10 \%$.

LNV unit root test findings are presented in Table 4. This approach allows for gradual structural break in intercept, trend or both. In any case of the three models one cannot accept the stationarity for different definition of RER. Nevertheless, the $\mathbf{t}$-statistics of EUR and TRY are close to the critical values of $10 \%$. The KSS test, findings of which given in Table 5 similar to LNV test results. The KSS test 
that allows for smooth transition is implemented on demeaned and detrended data, demeaned data and raw data. $\mathrm{t}$-statistics of three models of KSS nonlinear unit root test do not support any evidence in favor of stationary RER of AZN.

Table 4. Leybourne et al. (1998) unit root test result

\begin{tabular}{|l|l|l|l|}
\hline RER of AZN & $\begin{array}{l}\text { Transition } \\
\text { in mean }\end{array}$ & $\begin{array}{l}\text { Transition in mean } \\
\text { whit slope }\end{array}$ & $\begin{array}{l}\text { Transition in both } \\
\text { mean and slope }\end{array}$ \\
\hline USD & -2.442 & -3.281 & -3.085 \\
\hline EUR & -3.017 & -4.228 & -4.083 \\
\hline RUB & -2.453 & -3.051 & -3.807 \\
\hline TRY & -2.613 & -4.157 & -4.152 \\
\hline $\begin{array}{l}10 \% \text { critical values for } \\
\text { sample size of } 200\end{array}$ & -3.851 & -4.337 & -4.572 \\
\hline
\end{tabular}

Not: Critical values are based on Leybourne et al. (1998).

Table 5. Kapetanios et al. (2003) unit root test result

\begin{tabular}{|l|l|l|l|}
\hline RER of AZN & $\begin{array}{l}\text { Demeaned and } \\
\text { detrended data }\end{array}$ & Demeaned data & Raw data \\
\hline USD & -1.252 & 0.186 & 1.371 \\
\hline EUR & -1.875 & -1.387 & 0.776 \\
\hline RUB & -1.218 & -1.473 & -1.164 \\
\hline TRY & -1.139 & -2.522 & -0.782 \\
\hline $10 \%$ critical values & -3.13 & -2.66 & -1.92 \\
\hline
\end{tabular}

Not: Critical values are based on Kapetanios et al. (2003).

Table 6. Cuestas and Ordóñez (2014) unit root test result

\begin{tabular}{|l|l|}
\hline RER of AZN & t-statistics \\
\hline USD & -1.300 \\
\hline EUR & $\mathbf{- 4 . 0 6 2}$ \\
\hline RUB & -2.627 \\
\hline TRY & $-\mathbf{4 . 3 1 8}$ \\
\hline & -3.087 \\
\cline { 2 - 2 } $10 \%$ critical values for sample size of 100 and 250 & -3.110 \\
\hline
\end{tabular}

Not: Critical values are based on Cuestas and Ordóñez (2014). Bold numbers indicate rejection of the null hypothesis of unit root at the $10 \%$.

$\mathrm{CO}$ unit root test results are presented in Table 6. CO unit root test takes into account smooth transition and asymmetric adjustment. Demeaned and detrended data, demeaned data and raw data series of residuals do not have significant differences. Therefore, $\mathbf{t}-$ statistics of the models that run with these series are the 
same and support rejection of the null hypothesis of unit root against nonlinear and asymmetric adjustment when RER of AZN is defined by Euro or Turkish lira.

\section{Conclusion}

Existing literature on the validity of the PPP hypothesis in Azerbaijan covers limited studies that mostly use USD as numeriary currency, and have inconclusive results. This study provides an alternative perspective on this issue. By using linear and nonlinear unit root tests, validity of the PPP hypothesis between Azerbaijan and its major foreign trade partner countries is tested. Trading partner countries are the USA, European Union, Russia and Turkey. Results of linear unit root test with structural break supports RER stationarity when USD and Turkish lira are considered as numeriare currencies. Bierens' (1997) approach that allows the trend to be an almost arbitrary deterministic function of time provides evidence in favor of USD based RER stationarity. Nonlinear unit root test that models structural changes as monotonic and symmetric smooth transition path cannot reject null hypothesis of unit root for any RER series of AZN. CO nonlinear unit root test that takes into account structural change and asymmetric adjustment characteristics of RER provides evidence in favor of stationary Euro and Turkish lira based RER. As a result in brief, findings of study support the validity of the PPP hypothesis between Azerbaijan and its market economy dominated trading partners. But the validity of PPP hypothesis between Azerbaijan and its former centrally planned partner, Russia, is not supported by unit root test conclusions. The probable purposes for not holding PPP hypothesis between Azerbaijan and Russia might be foreign exchange regimes and domestic energy price controls put into practice in these countries.

\section{References and notes:}

Bahmani-Oskooee, M., Kutan, A.M. \& Zhou, S. (2008). Do Real Exchange Rates Follow a Nonlinear Mean Reverting Process in Developing Countries? Southern Economic Journal 74(4), 1049-1062.

Bahmani-Oskooee, M., Kutan, A.M. \& Zhou, S. (2009). Towards Solving the PPP Puzzle: Evidence from 113 Countries. Applied Economics 41(24), 3057-3066.

Bierens, H.J. (1997). Testing the Unit Root with Drift Hypothesis against Nonlinear Trend Stationarity, with an Application to the US Price Level and Interest Rate. Journal of Econometrics 81(1), 29-64.

Cuestas, J.C. \& Ordóñez, J. (2014). Smooth Transitions, Asymmetric Adjustment and Unit Roots. Applied Economics Letters, 14(21), 969-972.

Dickey, D.A. \& Fuller, W.A. (1979). Distribution of the Estimators for Autoregressive Time Series with a Unit Root. Journal of the American Statistical Association 74(366), 427-431.

Doğanlar, M. (2006). Long-run Validity of Purchasing Power Parity and Cointegration Analysis for Central Asian Countries. Applied Economics Letters 13(7), 457-461. 
Kapetanios, G., Shin, Y. \& Snell, A. (2003). Testing for a Unit Root in the Nonlinear STAR Framework. Journal of Econometrics 112(2), 359-379.

Leybourne, S., Newbold, P. \& Vougas, D. (1998). Unit Roots and Smooth Transitions. Journal of Time Series Analysis 19(1), 83-97.

Liew, V.K.-S., Chia, R.C.-J. \& Ling, T.-H. (2010). Long-run Validity of Purchasing Power Parity and Rank Tests for Cointegration for Central Asian Countries. Applied Economics Letters 17(11), 1073-1077.

Liew, V.K.-S., Puah, C.-H., Choong, C.-K. \& Lau, E. (2010). Revisiting Purchasing Power Parity for Central Asian Countries Using Threshold Cointegration Tests. Economics Bulletin 30(2), 1283-1292.

Solakoglu, E. G. (2006). Testing Purchasing Power Parity Hypothesis for Transition Economies. Applied Financial Economics 16(7), 561-568.

Telatar, E. \& Hasanov, M. (2009). Purchasing Power Parity in Transition Economies: Evidence from the Commonwealth of Independent States. Post-Communist Economies 21(2), 157-173.

Zivot, E. \& Andrews, D.W.K. (1992). Further Evidence on the Great Crash, the Oil-Price Shock, and the Unit-Root Hypothesis. Journal of Business \& Economic Statistics 10(3), 251-270.

\title{
Summary
}

\section{Testing Purchasing Power Parity Hypothesis for Azerbaijan}

\author{
Seymur Agazade \\ Recep Tayyip Erdoğan University, Turkey
}

This article examines the validity of purchasing power parity hypothesis for Azerbaijan. Econometric investigation uses linear and nonlinear unit root tests and are based on the time series characteristics of the real exchange rate of Azerbaijan's manat versus the national currencies of its major trading partners; USA, European Union, Russia and Turkey. Findings support the validity of the purchasing power parity hypothesis between Azerbaijan and its market economy dominated trading partners, but not support between Azerbaijan and its former centrally controlled partner.

Keywords: Purchasing Power Parity, Nonlinear Unit Root Tests, Structural Change, Asymmetric Adjustment, Azerbaijan. 